\title{
Dose intraarticular steroid injection increase the rate of infection in subsequent arthroplasty: grading the evidence through a meta-analysis
}

\author{
Dan Xing ${ }^{\dagger}$, Yang Yang ${ }^{\dagger}$, Xinlong Ma*, Jianxiong Ma*, Baoyi Ma and Yang Chen
}

\begin{abstract}
Background: Intraarticular steroid injections are widely used in joint arthritis. However, the data regarding an association between an increased risk for arthroplasty infection after an intraarticular steroid injection are still conflicting. We conducted a meta-analysis to evaluate the evidence from relevant studies that examine the relation between intraarticular steroid injections and infection rates in subsequent joint arthroplasty and to develop GRADE based recommendations for using the steroid before arthroplasty.

Methods: A systematic search of all studies published through August 2014 was conducted using the MEDLINE, EMBASE, OVID, ScienceDirect and Cochrane CENTRAL databases. The relevant studies that examined the relation between intraarticular steroid injections and infection rates in subsequent joint arthroplasty were identified. Demographic characteristics, infection rates and clinical outcomes were manually extracted from all of the selected studies. The evidence quality levels and recommendations were assessed using the GRADE system.

Results: Eight studies looking at hip and knee arthroplasties were included. Meta-analysis showed that patients with steroid injection before arthroplasty had a higher deep infection rate than patients without steroid injection $(\mathrm{OR}=2.13,95 \% \mathrm{Cl} 1.02-4.45)$, but no significant effect on superficial infection rate $(\mathrm{OR}=1.75,95 \% \mathrm{Cl}$ 0.74-4.16). The overall GRADE system evidence quality was very low, which lowers our confidence in their recommendations.
\end{abstract}

Conclusions: Intraarticular steroid injections may lead to increased deep infection rates of subsequent joint arthroplasty but not the superficial infection rates. Due to the poor quality of the evidence currently available, further studies are still required.

Keywords: Steroid, Injection, Infection, Arthroplasty, Meta-analysis

\section{Introduction}

Intraarticular steroid injections can be administered for diagnostic [1-4] and therapeutic reasons [5-8]. Particularly, they were widely used to alleviate inflammatory symptoms that can be associated with moderate or end-stage osteoarthritis of the joint. Compared with the injection of a long-acting anesthetic, steroids can be used for diagnostic purposes to distinguish intrinsic from extrinsic sources of pain such as that originating in the spine [1-4]. The duration and efficacy of pain relief then can be indicative of the source of pain [5-8]. Intraarticular steroid injections

\footnotetext{
*Correspondence: tjmuld@gmail.com; mjx969@163.com

${ }^{\dagger}$ Equal contributors

Department of Orthopaedics Institute, Tianjin Hospital, 406 Jiefang Nan Street, Hexi District, Tianjin 300211, China
}

can be helpful in clinical practice when patients with moderate or end-stage osteoarthritis are not willing or suitable to undergo an arthroplasty in the short term [9].

However, there have been several adverse effects reported with the use of steroid, such as tendon rupture $[10,11]$ and increased risk of joint infection in subsequent arthroplasty [12]. Given the potentially devastating outcomes of arthroplasty infection, determining whether such a relation exists is of high clinical importance. Several clinical studies have been conducted to examine this issue previously. Two studies $[13,14]$ showed more infections in a group of patients who had an intraarticular steroid injection in the hip before they had an arthroplasty. While, other two studies $[15,16]$ demonstrated that there was no increase in infection rates in patients 
who had arthroplasty after intraarticular injections of a steroid into the joint.

At present, the data regarding an association between an increased risk for arthroplasty infection after an intraarticular steroid injection are still conflicting. Therefore, the purpose of the present meta-analysis is to evaluate the evidence from relevant studies that examine the relation between intraarticular steroid injections and infection rates in subsequent joint arthroplasty and to develop GRADE (Grading of Recommendations, Assessment, Development, and Evaluation) based recommendations for using the steroid before arthroplasty $[17,18]$.

\section{Material and methods}

\section{Search strategy}

To assemble all of the relevant published studies, PRISMA compliant searches of MEDLINE, EMBASE, ScienceDirect, OVID, the Cochrane CENTRAL database and Google scholar were performed for all peer-reviewed studies published through Aug 2014 that examine the relation between intraarticular steroid injections and infection rates in subsequent joint arthroplasty. The following search terms were used to maximize the search specificity and sensitivity: injection, arthroplasty, infection, replacement, steroid, hip and knee.

Secondary searches of the unpublished literature were conducted by searching the WHO International Clinical Trials Registry Platform, UK National Research Register Archive, and Current Controlled Trials from their inception to August 1, 2014. The reference lists of all the full text papers were examined to identify any initially omitted studies. We made no restrictions on the publication language.

\section{Inclusive and exclusive criteria}

Studies were included if they compared the infection rates of joint arthroplasties in cohorts of joint arthroplasties that had previous intraarticular steroid injection, with the infection rates in cohorts of joint arthroplasties that had no previous steroid injection. Single case reports, reviews, and non-comparable studies were excluded.

\section{Study selection}

Two reviewers (D.X. and Y. Y.) independently screened the titles and abstracts for the eligibility criteria. Subsequently, the full text of the studies that potentially met the inclusion criteria were read and the literature was reviewed to determine the final inclusion. We resolved disagreements by reaching a consensus through discussion.

\section{Date extraction}

Two of the authors (D.X. and Y. Y.) independently extracted the following data from each full-text report using a standard data extraction form. The data extracted from studies included the title, authors, study design, prosthesis, steroid injection, time from injection to surgery, duration of follow-up, and outcomes parameters. The corresponding authors of the included studies were contacted to obtain any required information that was missing. The extracted data were verified by XL. M.

\section{Outcomes}

Deep infection rate and superficial infection rate were the outcomes of the present study.

\section{Assessment of methodological quality}

Following the Cochrane Handbook for Systematic Reviews of Interventions 5.0, the methodological quality of the included studies was independently assessed by two authors (D.X. and Y. Y.). Any disagreements were resolved by discussion. A third author (XL. M.) was the adjudicator when no consensus could be achieved. The methodological quality was assessed using the methodological index for non-randomized studies (MINORS) form [19], which was a valid instrument designed to assess the quality of comparative or non-comparative nonrandomized controlled trials.

\section{Data analysis}

We performed all of the meta-analyses with STATA 12.0 (Statacorp, college station, Tex). Odds ratio (OR) and 95\% confidence intervals (CIs) were used to evaluate the dichotomous outcomes. A P-value $<0.05$ was considered statistically significant.

Statistical heterogeneity was assessed using Q statistics. A fixed-effects (inverse variance) model was used when the effects were assumed to be homogenous $(P>0.05)$. $P<0.05$ implied statistical heterogeneity, and a random effects model was used in those circumstances.

\section{Evidence synthesis}

The evidence grade was determined using the guidelines of the GRADE (Grading of Recommendations, Assessment, Development, and Evaluation) working group [17]. Although the GRADE system acknowledges the primacy of RCTs, it also recognizes circumstances in which observational studies generate high quality evidence of treatment effects [20]. The GRADE system uses a sequential assessment of the evidence quality that is followed by an assessment of the risk-benefit balance and a subsequent judgment on the strength of the recommendations. The evidence grades are divided into the following categories: (1) high, which indicates that further research is unlikely to alter confidence in the effect estimate; (2) moderate, which indicates that further research is likely to significantly alter confidence in the effect estimate and may change the estimate; (3) low, which indicates that further research is likely to significantly alter confidence in the 
effect estimate and to change the estimate; and (4) very low, which indicates that any effect estimate is uncertain. Uniformity of the estimated effects across studies and the extent to which the patients, interventions, and outcome measures are similar to those of interest may lower or raise the evidence grade. As recommended by the GRADE working group, the lowest evidence quality for any of the outcomes was used to rate the overall evidence quality. The evidence quality was graded using the GRADEpro Version 3.6 software. The strengths of the recommendations were based on the quality of the evidence.

\section{Results}

\section{Search results}

A total of 1461 titles and abstracts were preliminarily reviewed, of which 8 studies [13,14,16,21-25] eventually satisfied the eligibility criteria (Figure 1). One of the eight studies [22] published in abstract form. Six studies $[13,14,16,22,23,25]$ evaluated infection rates in total hip arthroplasties (THA) and two studies $[21,24]$ in total knee arthroplasties (TKA).

\section{Quality assessment}

All studies had a high risk of bias resulting from study design limitations. The methodological quality assessments of the included studies used a MINORS form. The MINORS quality scores are presented in Table 1 . The mean score was 11.8 (range, 8-14), which corresponded to a
49\% score. This result indicated that there was considerable variability in the evidence base.

\section{Demographic characteristics}

In total, eight retrospective cohort studies with 2909 total patients were eligible for inclusion. The individual sample sizes ranged from 80 to 1317 patients. All included studies reported the rate of deep infection after arthroplasty, while six also reported the rate of supercritical infection. The demographic characteristics of the included studies are summarized in Table 2.

\section{Outcome analyses \\ Deep infection rate}

The deep infection rates for each analyzed studies were $0-10 \%$ in the injected group and $0-1.3 \%$ in the control group respectively. Meta-analysis showed that patients with steroid injection before arthroplasty had a higher deep infection rate than patients without steroid injection $(\mathrm{OR}=2.13,95 \%$ CI 1.02-4.45) (Figure 2).

\section{Superficial infection rate}

The superficial infection rates for each analyzed studies were $0-22.2 \%$ in the injected group and $0.4-11.1 \%$ in the control group respectively. Meta-analysis showed that steroid injection prior to joint arthroplasty had no significant effect on superficial infection rate $(\mathrm{OR}=1.75$, 95\% CI 0.74-4.16) (Figure 3).

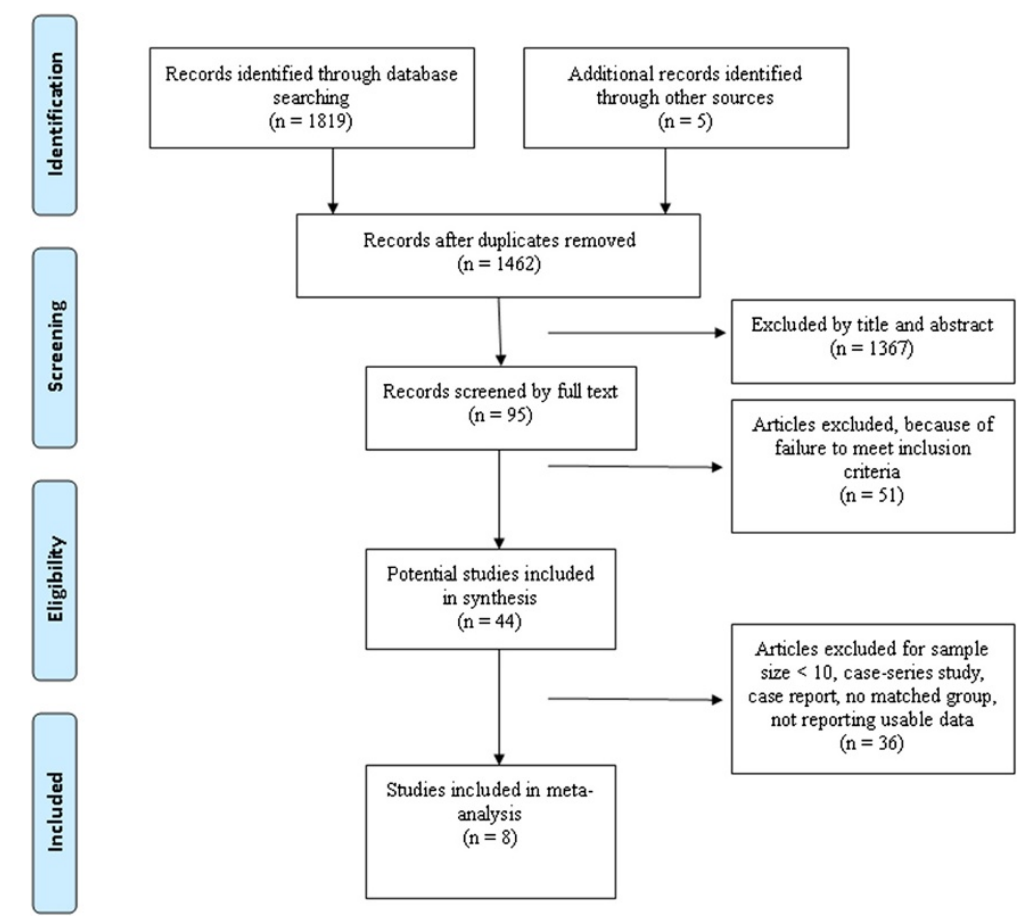

Figure 1 The study selection and inclusion process. 
Table 1 The study designs and MINORS appraisal scores for the included studies

\begin{tabular}{|c|c|c|c|c|c|c|c|c|c|c|c|c|c|c|}
\hline \multirow[t]{2}{*}{ Study } & \multirow[t]{2}{*}{ Study design } & \multicolumn{12}{|c|}{ MINORS methodological criteria } & \multirow[t]{2}{*}{ Total } \\
\hline & & 1 & 2 & 3 & 4 & 5 & 6 & 7 & 8 & 9 & 10 & 11 & 12 & \\
\hline Kaspar et al. & Retrospective cohort & 2 & 0 & 0 & 1 & 1 & 2 & 0 & 0 & 2 & 2 & 2 & 1 & 13 \\
\hline Papavasiliou et al. & Retrospective cohort & 2 & 1 & 0 & 1 & 0 & 2 & 1 & 0 & 2 & 2 & 1 & 1 & 13 \\
\hline Mclntosh et al. & Retrospective cohort & 2 & 0 & 0 & 1 & 1 & 2 & 0 & 0 & 2 & 2 & 1 & 1 & 12 \\
\hline Sreekumar et al. & Retrospective cohort & 1 & 1 & 0 & 1 & 0 & 2 & 0 & 0 & 2 & 2 & 0 & 1 & 10 \\
\hline Desai et al. & Retrospective cohort & 2 & 1 & 0 & 1 & 0 & 2 & 0 & 0 & 2 & 2 & 0 & 1 & 11 \\
\hline Haughton et al. & Retrospective cohort & 2 & 1 & 0 & 2 & 0 & 1 & 1 & 0 & 2 & 2 & 1 & 1 & 13 \\
\hline Meermans et al. & Retrospective cohort & 2 & 0 & 0 & 1 & 0 & 1 & 0 & 0 & 2 & 1 & 0 & 1 & 8 \\
\hline Croft et al. & Retrospective cohort & 2 & 1 & 0 & 2 & 0 & 2 & 0 & 0 & 2 & 2 & 2 & 1 & 14 \\
\hline
\end{tabular}

The MINORS criteria include the following items: (1) a clearly stated aim; (2) inclusion of consecutive patients; (3) prospective data collection; (4) endpoints appropriate to the aim of the study; (5) unbiased assessment of the study endpoint; (6) a follow-up period appropriate to the aims of the study; (7) less than $5 \%$ loss to follow-up; (8) prospective calculation of the sample size; (9) an adequate control group; (10) contemporary groups; (11) baseline equivalence of groups; and (12) adequate statistical analyses.

The items are scored as follows: 0 (not reported); 1 (reported but inadequate); or 2 (reported and adequate). The ideal global score for comparative studies is 24 .

Quality of the evidence and recommendation strengths

The two outcomes in this meta-analysis were evaluated using the GRADE system. The evidence quality for each outcome was low or very low (Table 3). Therefore, we agreed that the overall evidence quality was very low. This finding may lower the confidence in any recommendations.

\section{Discussion}

Infection is a major complication of a total joint arthroplasty. It occurs in only a small number of patients but results in substantial morbidity and a decline in functional outcome. An increased risk of postoperative infection after intraarticular steroid injection has been previously questioned with some clinical studies [13,14]. Several studies reported that intraarticular steroid injection may lead to increase arthroplasty infection rates. This may be due to failure of the steroid to dissolve which may thus persist and cause local immunosupression following joint arthroplasty $[13,24]$. Several studies reported that it may be related to contamination of the joint by the injection process [26]. However, Other studies demonstrated that there was no association between previous steroid injections and infection after subsequent joint arthroplasty $[16,21,23]$. Because infection rate of joint arthroplasty is an infrequent event [27], the failure of some studies that demonstrate such association may be related to the small number of patients included and hence low statistical power.

Meta-analysis is used as the main method in the research paper. It is more accurate and reliable than

Table 2 The demographic characteristics of the included studies

\begin{tabular}{|c|c|c|c|c|c|c|c|c|c|}
\hline \multirow[t]{2}{*}{ Study } & \multirow[t]{2}{*}{ Study design } & \multirow[t]{2}{*}{ Prosthesis } & \multirow[t]{2}{*}{ Steroid injection } & \multirow{2}{*}{$\begin{array}{l}\text { Time from } \\
\text { injection } \\
\text { to surgery }\end{array}$} & \multicolumn{2}{|c|}{$\begin{array}{l}\text { Deep infection } \\
\text { rate }\end{array}$} & \multicolumn{2}{|c|}{$\begin{array}{l}\text { Superficial } \\
\text { infection rate }\end{array}$} & \multirow[t]{2}{*}{$\begin{array}{l}\text { Follow-up } \\
\text { period }\end{array}$} \\
\hline & & & & & Injected & Control & Injected & Control & \\
\hline Kaspar et al. & $\begin{array}{l}\text { Retrospective } \\
\text { cohort }\end{array}$ & THA & 80 mg methylprednisolone & $0.5-42.9$ months & $4 / 40$ & $0 / 40$ & NR & NR & (9.9-86.2) months \\
\hline Papavasiliou et al. & $\begin{array}{l}\text { Retrospective } \\
\text { cohort }\end{array}$ & TKA & NR & $N R$ & $3 / 54$ & $0 / 90$ & $12 / 54$ & $10 / 90$ & 1 year \\
\hline Mclntosh et al. & $\begin{array}{l}\text { Retrospective } \\
\text { cohort }\end{array}$ & THA & $\begin{array}{l}\text { 6-40 mg drug } \\
\text { (not mentioned) }\end{array}$ & $112 \pm 81$ days & $3 / 224$ & $1 / 224$ & $11 / 224$ & $8 / 224$ & NR \\
\hline Sreekumar et al. & $\begin{array}{l}\text { Retrospective } \\
\text { cohort }\end{array}$ & THA & 80 mg depomedrone & 14 months & $0 / 68$ & $1 / 136$ & $0 / 68$ & $1 / 136$ & 25-33 months \\
\hline Desai et al. & $\begin{array}{l}\text { Retrospective } \\
\text { cohort }\end{array}$ & TKA & 80 mg depomedrone & 12 months & $0 / 90$ & $0 / 180$ & $2 / 90$ & $5 / 180$ & $1-6$ years \\
\hline Haughton et al. & $\begin{array}{l}\text { Retrospective } \\
\text { cohort }\end{array}$ & THA & $\begin{array}{l}80 \mathrm{mg} \text { depomedrone or } \\
40 \mathrm{mg} \text { triamcinolone }\end{array}$ & $N R$ & $4 / 254$ & $14 / 1063$ & $11 / 254$ & $4 / 1063$ & NR \\
\hline Meermans et al. & $\begin{array}{l}\text { Retrospective } \\
\text { cohort }\end{array}$ & THA & $\begin{array}{l}80 \text { mg depomedrone +5- } \\
15 \text { mg levobupivacaine }\end{array}$ & 12 months & $1 / 175$ & $1 / 175$ & $5 / 175$ & $7 / 175$ & 12-131 months \\
\hline Croft et al. & $\begin{array}{l}\text { Retrospective } \\
\text { cohort }\end{array}$ & THA & $\begin{array}{l}40 \mathrm{mg} \text { depomedrol }+4 \mathrm{ml} \\
2 \% \text { xylocaine }\end{array}$ & 5.9 months & $0 / 48$ & $0 / 48$ & NR & NR & 1.4-54.1 months \\
\hline
\end{tabular}

THA, total hip arthroplasty; TKA, total knee arthroplasty; NR, not reported. 


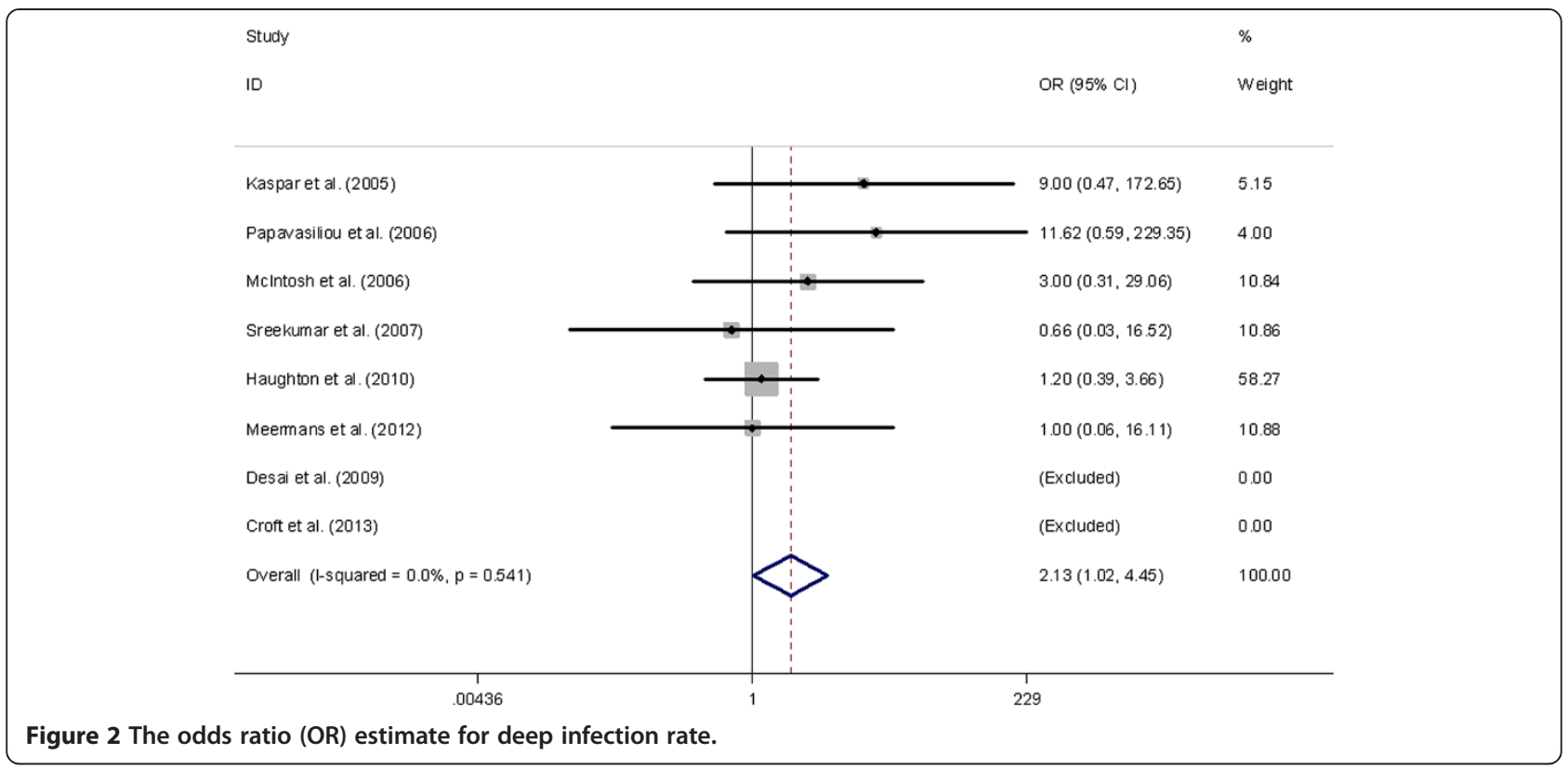

regression analysis or original papers. Meta-analysis can enhance statistical power and enlarger sample size by combining original studies, which could provide more robust evidence. Therefore, we conducted a metaanalysis to evaluate the evidence from relevant studies that examine the relation between intraarticular steroid injections and infection rates in subsequent joint arthroplasty. Furthermore, there have been no guidelines or recommendations for intraarticular steroid injections before joint arthroplasty. Therefore, there is a need for an evidence base to help surgeons make clinical decisions and develop optimal treatments before joint arthroplasty. To the best of our knowledge, this study is the first meta-analysis to use the GRADE system to evaluate the quality of the evidence evaluating the influence of intraarticular steroid injections on infection rate before joint arthroplasty.

Because of the challenges clinicians face from the lack of randomized surgical trials and the large number of observational surgical studies, retrospective studies were included in this meta-analysis. However, including retrospective studies in the present study introduces a high risk of bias. The methodological quality assessment identified a number of limitations to the current

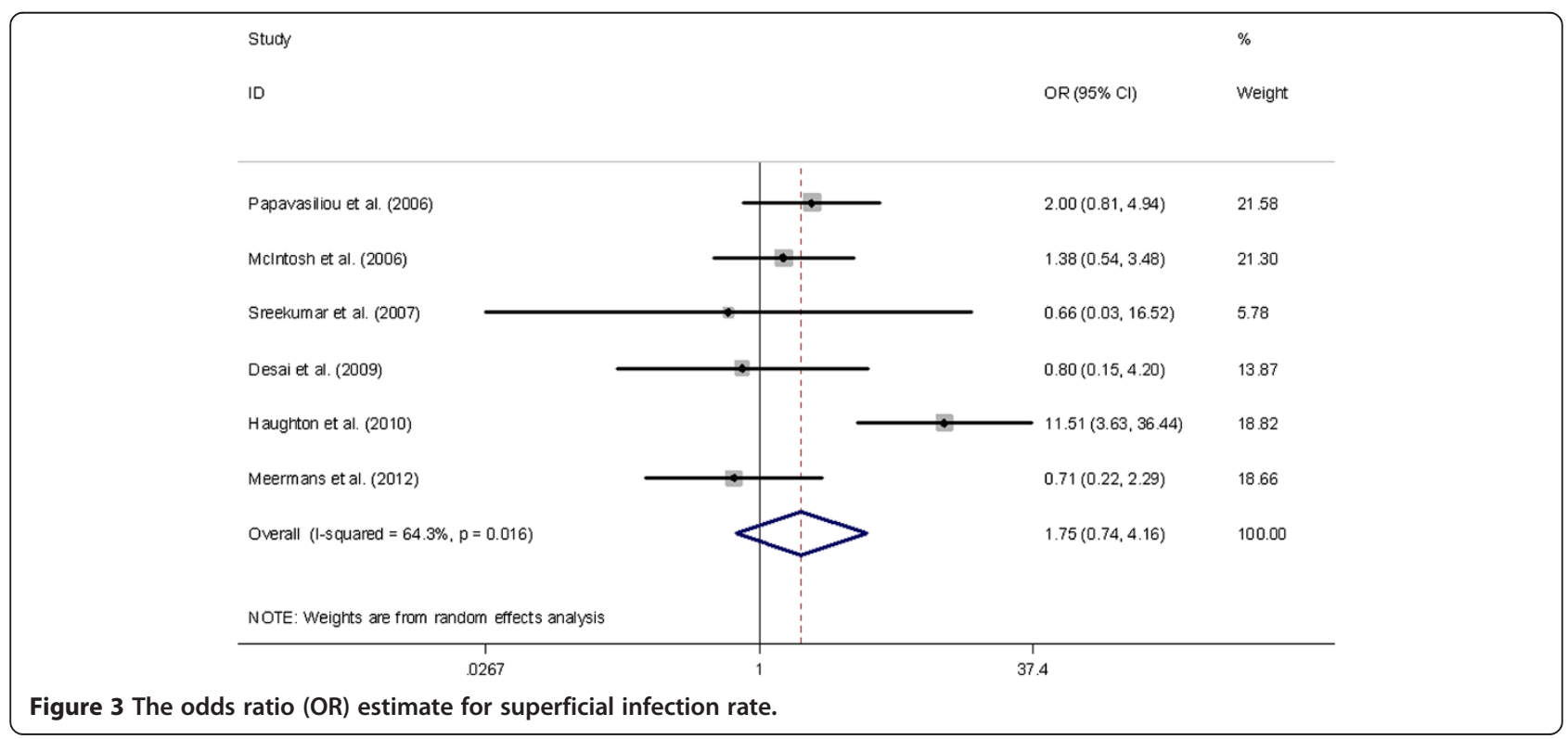


Table 3 The GRADE evidence quality for each outcome

\begin{tabular}{|c|c|c|c|c|c|c|c|c|c|c|c|}
\hline \multicolumn{7}{|c|}{ Quality assessment } & \multicolumn{2}{|c|}{ No. of patients } & \multirow{2}{*}{$\begin{array}{l}\text { Effect } \\
\text { OR } \\
(95 \% \mathrm{Cl})\end{array}$} & \multirow[t]{2}{*}{ Quality } & \multirow[t]{2}{*}{ Importance } \\
\hline Outcomes & $\begin{array}{l}\text { No of } \\
\text { studies }\end{array}$ & $\begin{array}{l}\text { Risk } \\
\text { of bias }\end{array}$ & Inconsistency & Indirectness & Imprecision & $\begin{array}{l}\text { Other } \\
\text { considerations }\end{array}$ & Injected & $\overline{\text { Control }}$ & & & \\
\hline $\begin{array}{l}\text { Superficial } \\
\text { infection } \\
\text { rate }\end{array}$ & 6 & Serious & Serious & $\begin{array}{l}\text { None } \\
\text { serious }\end{array}$ & $\begin{array}{l}\text { None } \\
\text { serious }\end{array}$ & None & $\begin{array}{l}41 / 865 \\
(4.7 \%)\end{array}$ & $\begin{array}{l}35 / 1868 \\
(1.9 \%)\end{array}$ & $\begin{array}{l}\text { OR 1.75 } \\
(0.74-4.16)\end{array}$ & $\begin{array}{l}\oplus \circ 0 \circ \\
\text { VERY } \\
\text { LOW }\end{array}$ & Important \\
\hline $\begin{array}{l}\text { Deep } \\
\text { infection } \\
\text { rate }\end{array}$ & 8 & $\begin{array}{l}\text { None } \\
\text { serious }\end{array}$ & None serious & $\begin{array}{l}\text { None } \\
\text { serious }\end{array}$ & $\begin{array}{l}\text { None } \\
\text { serious }\end{array}$ & None & $\begin{array}{l}15 / 953 \\
(1.6 \%)\end{array}$ & $\begin{array}{l}17 / 1956 \\
(0.9 \%)\end{array}$ & $\begin{array}{l}\text { OR } 2.13 \\
(1.02-4.45)\end{array}$ & $\begin{array}{l}\oplus \oplus \circ \circ \\
\text { LOW }\end{array}$ & Important \\
\hline
\end{tabular}

OR, odds ratio.

evidence base. Combining the results of the observational studies could cause significant bias. To some extent, the observational studies included in this study may overestimate the actual effect. Moreover, confounding factors that should be balanced by randomized methods disturbed the intervention effect in the retrospective studies. Therefore, most of the included studies had relatively high methodological assessment risks, which may have influenced the accuracy and reliability of the pooled results.

Some degree of clinical heterogeneity was induced by the different surgical technologies used, surgical site, medical co-morbidities, nutritional status of patients, surgical duration, admission to the hospital from a healthcare facility, pre-surgical medical status, follow-up times, surgeon's experience, use of drains and diagnostic criteria for indection. Heterogeneity may have been caused by poor study design. Because of limited information got from original studies, heterogeneity cannot be completely resolved. Accordingly, although the results of the meta-analysis should be considered appropriate, methodological quality defects and clinical heterogeneity should be considered when interpreting the findings.

The most important finding of the present meta-anslysis was that intraarticular steroid injection had statistically significant effect on the deep infection rates of subsequent joint arthroplasty but not on superficial infection rates, suggesting that such practice should not be taken lightly. Papavasiliou et al. [24] showed a statistically higher deep infection rate in TKA that had a previous steroid injection as compared to those who had no previous injection. However, Desai et al. [21] showed no increased incidence of deep or superficial infection in TKA after a prior steroid injection. Meermans et al. found no differences between the injected and control groups for the rate of deep or superficial infection in THA.

Steroids can provide symptomatic control in the short term and may allow surgery to be delayed until a more appropriate time. The problem is that it is not possible to predict which patients will respond positively to an injection. Several studies $[13,14]$ found a greater rate of infection in THA performed after a previous steroid injection. However, it is unclear which component of the injection procedure may be culpable: the arthrography dye, the steroid or its depot vehicle, contamination of the local anesthetic, the invasiveness of a needle through prepared skin, any breech of sterile technique, or the time between the steroid injection and the arthroplasty [23]. Because of poor study design and limitations, the GRADE evidence quality for deep and superficial infection rate was low and very low respectively. Because of the insufficient quality of evidence, the effect estimate is uncertain and has a lower GRADE recommendation strength.

In the present study, the GARDE evidence quality was very low, which means that we were very uncertain about the estimates. The lowest GRADE evidence quality will lower our confidence in recommendation. Therefore, we would better make clinical decision based on individual characteristics of the patients.

The primary limitations of this meta-analysis include the following: (1) the statistical efficacy could be improved by including more studies. Owing to the finite of included studies, subgroup analysis can not be performed on TKA or THA. It may exert instability on consistency of outcomes. (2) poorly designed retrospective studies were more likely to suffer from various types of bias. The pooled results may have significant bias originated from limitations of original retrospective studies; (3) To some extent, clinical heterogeneity can not be resolved completely, such as injection protocols, timing of injections, number of injections and surgical experience. (4) the overall GRADE quality of evidence was very low, which lowers confidence in any subsequent recommendations. Although we used the GRADE system to evaluate the evidence quality and recommendation strengths, judgment is still required.

\section{Conclusion}

From this meta-analysis and grading of the evidence, the present study offers useful conclusions and demonstrates that intraarticular steroid injections may lead to increased deep infection rates of subsequent joint arthroplasty but not the superficial infection rates. However, the overall GRADE evidence quality was very low, which will lower 
our confidence in recommendation strengths. Further high-quality studies are still required to validate the results.

\section{Competing interests}

The authors declare that they have no competing interests.

\section{Authors' contributions}

The design of the study was done by XLM and JXM. DX and YY prepare the manuscript and assisted in the study processes. $Y C$ and BYM assisted in the data collections. All authors read and approved the final manuscript.

\section{Acknowledgement}

The authors thank Professor Edmund Y.S. Chao for his helpful advice on researching the unpublished literature.

This study was supported by grants from the National Natural Science Foundation of China (No.81301121).

Received: 25 September 2014 Accepted: 22 October 2014

Published online: 13 November 2014

\section{References}

1. Crawford RW, Gie GA, Ling RS, Murray DW: Diagnostic value of intra-articular anaesthetic in primary osteoarthritis of the hip. J Bone Joint Surg Br 1998, 80(2):279-281.

2. Faraj $A A$, Kumaraguru P, Kosygan K: Intra-articular bupivacaine hip injection in differentiation of coxarthrosis from referred thigh pain: a 10 year study. Acta Orthop Belg 2003, 69(6):518-521.

3. Kaspar J, Kaspar S, Orme C, de Beer JV: Intra-articular steroid hip injection for osteoarthritis: a survey of orthopedic surgeons in Ontario. Can J Surg 2005, 48(6):461-469.

4. Kleiner JB, Thorne RP, Curd JG: The value of bupivicaine hip injection in the differentiation of coxarthrosis from lower extremity neuropathy. I Rheumatol 1991, 18(3):422-427.

5. Creamer P: Intra-articular corticosteroid treatment in osteoarthritis. Curr Opin Rheumatol 1999, 11(5):417-421.

6. Neustadt DH: Local steroid injections: comment on the American College of Rheumatology guidelines for the management of osteoarthritis of the hip and on the letter by Swezey. Arthritis Rheum 1997, 40(10):1914-1915.

7. Plant MJ, Borg AA, Dziedzic K, Saklatvala J, Dawes PT: Radiographic patterns and response to corticosteroid hip injection. Ann Rheum Dis 1997, 56(8):476-480

8. Swezey RL: Comment on the American College of Rheumatology guidelines for osteoarthritis of the knee and hip. Arthritis Rheum 1996, 39(12):2083

9. Recommendations for the medical management of osteoarthritis of the hip and knee: 2000 update. American College of Rheumatology Subcommittee on Osteoarthritis Guidelines. Arthritis Rheum 2000, 43(9):1905-1915

10. Ismail AM, Balakrishnan R, Rajakumar MK, Lumpur K: Rupture of patellar ligament after steroid infiltration. Report of a case. J Bone Joint Surg $B$ 1969, 51(3):503-505.

11. Sweetnam R: Corticosteroid arthropathy and tendon rupture. J Bone Joint Surg Br 1969, 51(3):397-398.

12. Berbari EF, Hanssen AD, Duffy MC, Steckelberg JM, Ilstrup DM, Harmsen WS, Osmon DR: Risk factors for prosthetic joint infection: case-control study. Clin Infect Dis 1998, 27(5):1247-1254

13. Kaspar $\mathrm{S}$, de $\mathrm{V}$ de Beer J: Infection in hip arthroplasty after previous injection of steroid. J Bone Joint Surg Br 2005, 87(4):454-457.

14. Mclntosh AL, Hanssen AD, Wenger DE, Osmon DR: Recent intraarticular steroid injection may increase infection rates in primary THA. Clin Orthop Relat Res 2006, 451:50-54.

15. Chitre AR, Fehily MJ, Bamford DJ: Total hip replacement after intra-articular injection of local anaesthetic and steroid. J Bone Joint Surg Br 2007, 89(2):166-168.

16. Sreekumar $R$, Venkiteswaran $R$, Raut $V$ : Infection in primary hip arthroplasty after previous steroid infiltration. Int Orthop 2007, 31(1):125-128.

17. Atkins $D$, Best $D$, Briss PA, Eccles $M$, Falck-Ytter $Y$, Flottorp $S$, Guyatt $G H$ Harbour RT, Haugh MC, Henry D, Hill S, Jaeschke R, Leng G, Liberati A, Magrini N, Mason J, Middleton P, Mrukowicz J, O'Connell D, Oxman AD, Phillips B, Schunemann HJ, Edejer T, Varonen H, Vist GE, Williams JJ, Zaza S:
Grading quality of evidence and strength of recommendations. BMJ 2004, 328(7454):1490.

18. Atkins D, Eccles M, Flottorp S, Guyatt GH, Henry D, Hill S, Liberati A, O'Connell D, Oxman AD, Phillips B, Schunemann H, Edejer TT, Vist GE, Williams JJ: Systems for grading the quality of evidence and the strength of recommendations I: critical appraisal of existing approaches The GRADE Working Group. BMC Health Serv Res 2004, 4(1):38.

19. Slim K, Nini E, Forestier D, Kwiatkowski F, Panis Y, Chipponi J: Methodological index for non-randomized studies (minors): development and validation of a new instrument. ANZ J Surg 2003, 73(9):712-716.

20. Kunz R: Randomized trials and observational studies: still mostly similar results, still crucial differences. J Clin Epidemiol 2008, 61(3):207-208.

21. Desai A, Ramankutty S, Board T, Raut V: Does intraarticular steroid infiltration increase the rate of infection in subsequent total knee replacements? Knee 2009, 16(4):262-264.

22. Haughton D, Davey C, Sapherson D: Is hip injection safe and effective: the patients perspective? Rheumatology 2010, 1(49):64

23. Meermans G, Corten K, Simon JP: Is the infection rate in primary THA increased after steroid injection? Clin Orthop Relat Res 2012, 470(11):3213-3219.

24. Papavasiliou AV, Isaac DL, Marimuthu R, Skyrme A, Armitage A: Infection in knee replacements after previous injection of intra-articular steroid. J Bone Joint Surg Br 2006, 88(3):321-323.

25. Croft S, Rockwood P: Risk of intraarticular steroid injection before total hip arthroplasty. Curr Orthop Pract 2013, 2(24):185.

26. Charalambous CP, Tryfonidis M, Sadiq S, Hirst P, Paul A: Septic arthritis following intra-articular steroid injection of the knee-a survey of current practice regarding antiseptic technique used during intra-articular steroid injection of the knee. Clin Rheumatol 2003, 22(6):386-390.

27. Asaid R, Williams I, Hyde D, Tiang T: Infection rates following hip and knee joint arthroplasty: large referral centre versus a small elective-only hospital. Eur J Orthop Surg Traumatol 2013, 23(2):165-168

doi:10.1186/s13018-014-0107-2

Cite this article as: Xing et al: Dose intraarticular steroid injection increase the rate of infection in subsequent arthroplasty: grading the evidence through a meta-analysis. Journal of Orthopaedic Surgery and Research 2014 9:107.

\section{Submit your next manuscript to BioMed Central and take full advantage of:}

- Convenient online submission

- Thorough peer review

- No space constraints or color figure charges

- Immediate publication on acceptance

- Inclusion in PubMed, CAS, Scopus and Google Scholar

- Research which is freely available for redistribution 